See discussions, stats, and author profiles for this publication at: https://www.researchgate.net/publication/324263680

\title{
Placebo analgesia persists during sleep: An experimental study
}

Article in Progress in Neuro-Psychopharmacology and Biological Psychiatry · April 2018

DOl: 10.1016/j.pnpbp.2018.03.027

CITATIONS

5 authors, including:

0

Pierre Rainville

Université de Montréal

161 PUBLICATIONS 10,016 CITATIONS

SEE PROFILE

Gilles J Lavigne

Université de Montréal

348 PUBLICATIONS 16,457 CITATIONS

SEE PROFILE

Some of the authors of this publication are also working on these related projects:

Project Restless legs syndrome View project

Project Genetics of REM sleep behavior disorder and conversion to synucleinopathies View project
READS

179

Jacques Montplaisir

Université de Montréal

614 PUBLICATIONS 34,447 CITATIONS

SEE PROFILE 


\section{Placebo analgesia persists during sleep: an experimental study}

Accepted for publication in Progress in Neuro-Psychopharmacology \& Biological Psychiatry, 2018-03-31

Authors: Danièle Laverdure-Dupont ${ }^{1,2}$, Pierre Rainville* ${ }^{\star 3,4}$, Cédric Renancio ${ }^{1,2}$, Jacques Montplaisir ${ }^{2,5}$, Gilles Lavigne ${ }^{2,3}$

\section{Affiliations:}

'Département de Neuroscience, Faculté de Médicine, Université de Montréal, Canada, H3T 1J4

${ }^{2}$ Centre d'étude du Sommeil et des Rythmes Biologiques, Hôpital du SacréCœur, Montréal, Canada, H4J $1 \mathrm{C} 5$

${ }^{3}$ Département de Stomatologie, Faculté de Médecine Dentaire and Groupe de Recherche sur le Système Nerveux Central (GRSNC), Université de Montréal, Canada, H3T 1J4

${ }^{4}$ Centre de Recherche de l'Institut Universitaire de Gériatrie de Montréal (CRIUGM), Canada, H3W 1W4

${ }^{5}$ Département de Psychiatrie, Université de Montréal, Canada, H3T 1J4

* Corresponding author: Pierre Rainville, PhD., pierre.rainville@umontreal.ca, Centre de recherche de l'institut universitaire de gériatrie de Montréal (CRIUGM), 4565 Ch Queen-Mary, Montréal (Qué), H3W 1W5, Canada.

Acknowledgements: This work was supported by the Institute of Neurosciences, Mental Health and Addiction of the Canadian Institutes of Health Research (Placebo New Emerging Team) and the Québec Pain Research Network (Fonds de la Recherche du Québec - Santé, FRQS). PR received salary support as a Chercheur National from the FRQS. We thank Christiane Manzini, Ajar Aloui, and Sophie Pelletier for technical help.

Conflicts of Interest: The authors declare no competing financial interests. 


\section{ABSTRACT}

Although placebo analgesia is a well-recognized phenomenon with important clinical implications, the possibility that placebo effects occur during sleep has received little attention. This experimental study examined whether responsiveness to acute heat pain stimuli applied during sleep could be reduced following a placebo conditioning procedure administered before sleep. Healthy individuals $(n=9)$ underwent polysomnographic recordings for one habituation night followed by one placebo analgesia night and one control night in counterbalanced order. Conditioning induced robust analgesia expectations before the placebo night. In the morning after the placebo night, participants reported less nocturnal pain, anxiety, and associated sleep disturbance (all p's<0.05) compared to the control night. Furthermore, placebo induction produced a $10 \%$ reduction in brain arousals evoked by noxious stimuli during rapid-eye-movement ( $R E M)$ sleep ( $p=0.03$ ), consistent with our previous findings suggesting that analgesia expectations are reprocessed during REM sleep. In contrast, arousals increased by $14 \%$ during slow wave sleep (SWS) ( $p=0.02)$. In the morning after the last recording night, placebo testing administered as a manipulation check confirmed that typical placebo analgesic responses were produced during waking ( $p$ 's $<0.05$ ). These results suggest that analgesia expectations developed before sleep reduced nocturnal pain perception and subjective sleep disturbances and activated brain processes that modulate incoming nociceptive signals differentially according to sleep stage. These results need to be replicated in future studies exploring how analgesia expectations may be reactivated during different sleep stages to modulate nociceptive responses. 


\section{INTRODUCTION}

Expectations have a profound influence on human perception. In the waking state, placebo analgesia is an example of cognitive modulation driven by expectations of a positive treatment outcome (e.g., $[1 ; 8 ; 16 ; 42 ; 52 ; 64])$. Although classical conditioning appears sufficient to generate placebo responses involving unconscious physiological functions, the modulation of pain perception by a placebo generally involves a conscious anticipation of relief $([9 ; 15])$.

Sleep is a state of reduced awareness in which higher-order processing of external stimuli is generally thought to be largely suppressed. Given that conscious processing of placebo cues and associated outcomes may be necessary for placebo responses to occur, placebo effects would be expected to be suppressed during sleep. However, once learning has occurred, expectancy may affect later outcomes through unconscious processes ([28;31;43]). Learned placebo analgesia responses might then be expressed without explicit processing of pain-related cues or conscious evocation of relief expectancy.

The brain may process external stimuli during both rapid-eye-movement sleep (REM) and slow-wave sleep (SWS), and the reduced engagement of frontal cortices in response to such inputs is generally interpreted as a sleep-protecting function that prevents waking $([14 ; 18 ; 56 ; 63])$. Brain activity during REM sleep has also been associated with cognitive processes ([19;25;38;49]), including offline reprocessing of recent memories $([36 ; 59])$. We previously suggested that REM sleep may be involved in the reprocessing of relief expectations generated prior to sleep ([33;34]). Placebo mechanisms may involve sleep-related processing that results from unconscious reactivation of learned expectations that may alter responses to noxious stimuli.

In the present study, healthy participants underwent placebo conditioning on the evening before sleep and were subjected to noxious thermal stimuli while 
sleeping the following night. We tested the hypothesis that placebo conditioning and relief expectations induced prior to sleep would reduce nocturnal pain, anxiety, and sleep disturbance reported the following morning. Polysomnography was used to assess brain arousals in response to nociceptive stimuli across sleep stages. We expected a reduction in stimulus-induced arousals during sleep, and especially during REM sleep, in response to a possible reactivation of relief expectations.

\section{MATERIALS AND METHODS}

\subsection{Participants}

Eleven participants were recruited from the University of Montreal campus, and all procedures were conducted in a sleep laboratory at the Centre for Advanced Research in Sleep Medicine of the Hôpital du Sacré-Coeur de Montréal (http://www.ceams-carsm.ca/en). Data from one participant were incomplete due to equipment failure, and data from another one were discarded due to unreliable pain reports in the calibration phases (see below). The final data set included 9 healthy right-handed volunteers ( 5 females, mean age $=22.8 \pm 0.6$ years) free of medication except for contraceptive pills for 3 women. Participants had a regular sleep-wake cycle (7-8 hours per night, with bedtime between 10:00 PM and 12:00 AM), which they maintained during the entire course of the study. They were asked to abstain from alcohol and caffeine $24 \mathrm{~h}$ before and during each of the 3 testing sessions. All experimental procedures met the guidelines of the latest revision of the Declaration of Helsinki and were approved by the Institutional Research Ethics Board. All participants signed a consent form and were debriefed at the end of the study. 


\subsection{Procedures and Design}

Contact heat pain was induced on the ventral forearm with a $3 \mathrm{~cm}^{2}$ thermal probe (TSA-II NeuroSensory Analyzer; Medoc Ltd.). Heat stimuli lasted 17 s, including a $7 \mathrm{~s}$ plateau at the target temperature and two $5 \mathrm{~s}$ up/down ramps from/to a baseline temperature of $32^{\circ} \mathrm{C}$. In waking state, successive stimuli were preceded by a $5 \mathrm{~s}$ auditory countdown and separated by a $60 \mathrm{~s}$ interval. In the calibration blocks (a total of 6 , Figure 1), sequences of ascending stimuli $\left(1^{\circ} \mathrm{C}\right.$ increments) were delivered to each arm starting at $41^{\circ} \mathrm{C}$ up to the participant's tolerance threshold or a maximum of $50^{\circ} \mathrm{C}$. The pain produced by each stimulus was rated on a visual analog scale (VAS; see below) and a stimulus-response function was obtained for each participant to determine the individual temperatures administered in the placebo conditioning and placebo phases.

The within-subject design included three overnight sessions from about 8:00 PM to 9:00 AM (Figure 1). The first and second sessions took place on consecutive nights, with the third session one week later. The first session served as a habituation night to acclimatize participants to the sleep laboratory and to initiate placebo conditioning. In the conditioning block for the first session, the same inert cream was applied to the control and placebo site. The cream was described to the participant as a long-lasting topical analgesic when applied to the placebo site, and an inert compound when applied to the control site. A series of 8 stimuli were then administered to each site. Stimulus intensity at the control site was adjusted based on the first calibration block to produce moderate pain (corresponding to a rating of 40-60/100 VAS intensity units). At the placebo site, stimulus intensity was surreptitiously decreased by $2^{\circ} \mathrm{C}$. Expected, concurrent, and retrospective pain ratings were collected for each site (see below).

Participants were then prepared for polysomnographic recording with standard electroencephalographic (EEG), electrooculographic, and electromyographic settings. Participants were informed that no thermal stimuli would be applied 
during the first night. The light was turned off at 11:00 PM, and participants were woken up at 7:00 AM.

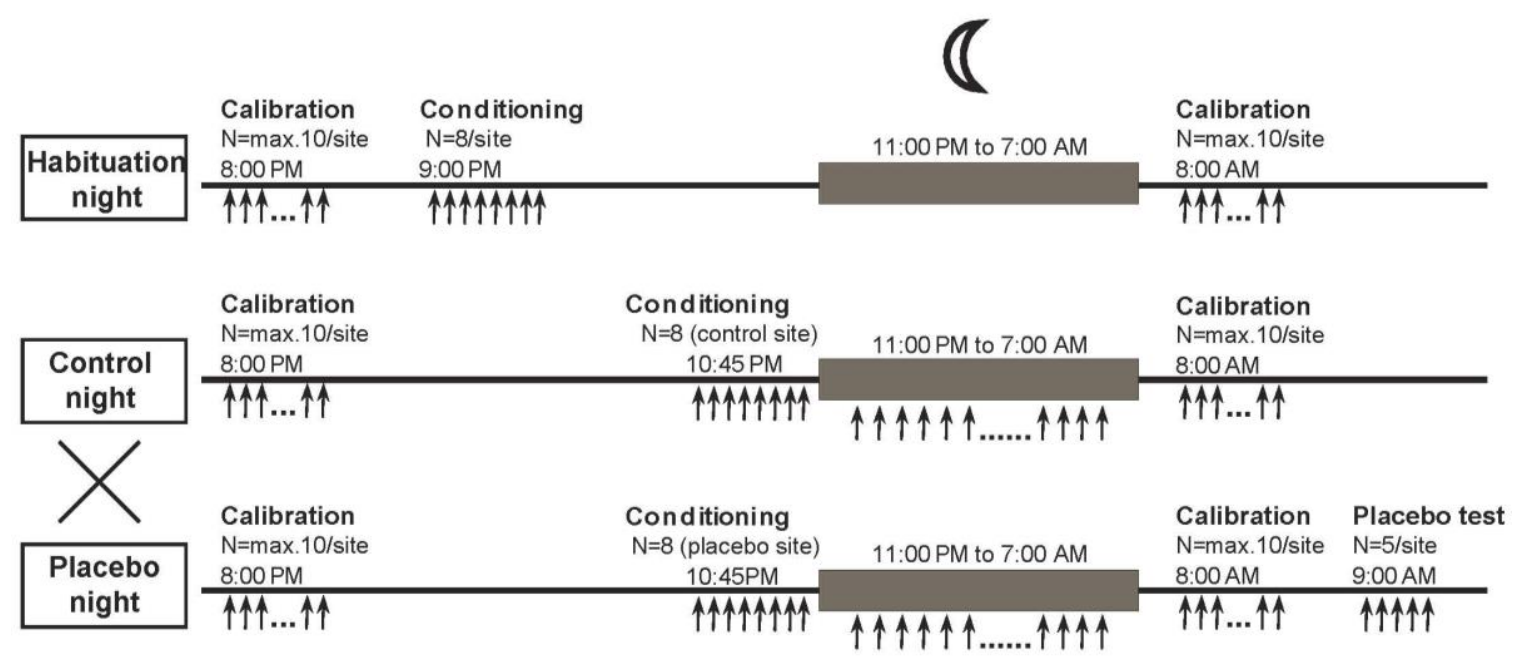

Figure 1. Experimental design. Six thermal calibration blocks were performed in the evening and morning of each of the three nights spent in the laboratory to control for potential differences in pain sensitivity. A conditioning procedure was administered before each night to generate robust experience-driven expectations of pain relief by the placebo treatment. No nocturnal thermal stimuli were administered during the first night (habituation). Control and placebo conditions were administered in the second and third nights (counterbalanced between participants), and nociceptive heat stimuli of the same intensity were administered during both nights across REM and non-REM sleep stages. Placebo analgesia was assessed in waking state after the calibration block on the last morning. Arrows represent nociceptive stimuli.

In the experimental sessions (control and placebo nights), nociceptive stimuli were administered with a contact probe stably attached to the participant's forearm. To avoid alerting participants to incoming stimuli, the apparatus was placed in an adjacent room and connected to the probe via a long cable passing 
through a wall opening. Just before sleep on the control night, only the neutral cream described as inert was applied to the control site, followed by 8 stimuli at moderate pain intensity according to the calibration phase. Just before sleep on the placebo night, the same cream was applied to the placebo site, but with the suggestion that it would provide long-lasting analgesia. Eight stimuli were then delivered to the placebo site with intensity surreptitiously reduced by $2^{\circ} \mathrm{C}$ below that for the control site. The light was turned off at 11:00 PM. Nocturnal heat stimuli of equal intensity, corresponding to moderate pain, were applied on the control and placebo nights. Stimuli were delivered pseudorandomly across stage 2, SWS, and REM sleep to obtain comparable distributions between the two nights. The first stimulus was delivered after participants attained the first stable period of SWS. Stimuli were then administered after a sleep stage was stable for at least 2 minutes and at intervals of at least 2 minutes. Participants were woken up at 7:00 AM and the calibration procedure was repeated.

On the morning of the last session, a placebo test block was conducted in waking state after the final calibration. The placebo and control creams were reapplied and the conditioning block procedure used on the habituation night was repeated, but with 5 stimuli of equal intensity (moderate pain) applied to both sites. Expected, concurrent, and retrospective subjective pain ratings were collected for each site to confirm the placebo effect in waking state (i.e., manipulation check).

\subsection{Subjective Ratings}

Subjective ratings of pain intensity and unpleasantness (expected, concurrent, and retrospective) were acquired with a $15 \mathrm{~cm}$ VAS ([51]) translated into French. The descriptors "no pain sensation" and "most intense pain imaginable" and "not at all unpleasant" and "most unpleasant imaginable" were used as anchors on the pain intensity and unpleasantness scales, respectively. Expected pain intensity and unpleasantness were obtained by asking, "What do you expect the 
pain intensity/unpleasantness to be without/with the analgesic cream?"

Concurrent ratings of pain intensity and unpleasantness were obtained after each stimulus using the same scales. Retrospective ratings were acquired approximately 2 min after each block completion by asking, "Retrospectively, what was the overall pain intensity/unpleasantness you felt without/with the analgesic cream?"

Just before the light was turned off on the control and placebo nights, expectations of nocturnal pain, sleep disturbance, and anxiety were assessed with the following questions: "What do you expect the pain intensity/unpleasantness to be during the night?"; "How much do you expect the experimental pain to disturb your sleep?"; and "When you think of the coming night, how would you rate your anxiety?" At morning wake-up, participants were asked to retrospectively rate their nocturnal experience on the same scales in response to the following questions: "What was the intensity/unpleasantness of the pain you felt during the night?"; "How much did the experimental pain disturb your sleep?"; "How many stimuli do you remember feeling during the night?"; and "How would you rate your anxiety during the night?"

\subsection{Polysomnography}

Recording electrodes were placed according to the International 10-20 System ([27;44]) and positioned at PF1, PF2, F3, F4, Fz, C3, C4, Cz, O1, and O2, with linked earlobes $(\mathrm{A} 1+\mathrm{A} 2)$ as a reference. An experienced technician installed and removed the electrodes and performed online monitoring of polysomnographic activity in an adjacent room during the night. To ensure blinding, the technician did not attend the calibration or conditioning phases of the paradigm and did not further interact with the participants or the experimenter during the behavioral data recording (i.e., rating and questionnaires). The technician was also blind to the experimental conditions during offline scoring, which was performed according to standard guidelines ([53]) to assess sleep 
architecture and identify responses evoked by the noxious heat stimuli during each sleep stage. An arousal response was recorded when a change lasting more than $3 \mathrm{~s}$ and within a $15 \mathrm{~s}$ window starting from stimulus onset was identified in the polysomnographic recordings ([3][35]).

In addition, the following parameters were extracted for each of the 3 nights. Sleep latency was defined as the time in minutes from the moment when the light was turned off to the first sleep episode. Sleep duration ( $\mathrm{min}$ ) corresponded to the total sleep time, as determined by polysomnography. Sleep efficiency (\%) was calculated by dividing the sleep duration by the overall time from sleep onset to final morning wake-up. The relative durations of stage 2 sleep, SWS (stages 3 and 4), and REM sleep were expressed as the percentage of time spent in each stage relative to the total sleep time. REM sleep latency was defined as the delay in minutes between sleep onset and the first episode of REM sleep.

\subsection{Statistical Analyses}

Means \pm SEM are presented. A 3 (sessions) $\times 2$ (time of day) $\times 2$ (conditions) ANOVA for repeated measures with Huynh-Feldt correction was used to analyze the calibration data. Paired T-tests were used to compare subjective ratings between control and placebo conditions. ANOVA for repeated measures was used to compare sleep parameters between the nights. Total numbers of stimulations per night and for each sleep stage were pooled across all participants and compared with paired T-tests across conditions. Yates-corrected Chi-square tests were used to compare proportions of brain arousals between control and placebo nights [for each sleep stage. 


\section{RESULTS}

\subsection{Baseline Pain Sensitivity}

In the evening and morning of each of the 3 sessions, all participants completed a calibration block to determine their moderately painful temperature and to assess changes in baseline pain sensitivity throughout the study. The overall average heat pain threshold was $44.9 \pm 0.5^{\circ} \mathrm{C}$, with no significant difference in sensitivity between control and placebo stimulus sites ( $45.0 \pm 0.6$ vs. $44.8 \pm$ $0.5^{\circ} \mathrm{C} ; \mathrm{F}(1,7)=0.51, \mathrm{p}=0.50$ ), nor between evening and morning calibration blocks (44.8 \pm 0.6 vs. $45.0 \pm 0.5^{\circ} \mathrm{C} ; \mathrm{F}(1,7)=0.36, p=0.57$ ). Participants tended to be slightly more sensitive to heat pain in the habituation session (session 1: $44.3 \pm$ $0.7^{\circ} \mathrm{C}$, session 2: $45.1 \pm 0.5^{\circ} \mathrm{C}$, session $\left.3: 45.3 \pm 0.5^{\circ} \mathrm{C} ; \mathrm{F}(2,14)=3.67, \mathrm{p}=0.08\right)$, but no significant variation was found between control and placebo nights performed as the second or third session (main effect of experimental night order: $F(1,7)=0.04, p=0.85$; interaction between session and night order: $F(2,14)=0.68, p=0.48)$. No other significant main effect or interaction was observed.

Based on the first calibration block, the temperature required to induce moderate pain was estimated for each participant. Throughout the study, the average temperatures delivered to control and placebo sites in the conditioning trials were $48.6 \pm 0.2^{\circ} \mathrm{C}$ and $46.6 \pm 0.2^{\circ} \mathrm{C}$, corresponding to mean pain intensity ratings of $46.1 / 100 \pm 4.8$ and $26.6 / 100 \pm 3.8$ VAS units, respectively.

\subsection{Placebo Conditioning}

In addition to verbal suggestions of pain relief, conditioning was used to strengthen participant expectations of treatment effectiveness by surreptitiously decreasing the temperature applied to the placebo site. In the first session, a conditioning block was performed with 8 stimuli at each site. Beforehand, 
participants were asked to rate how much pain they expected to feel at the control and placebo sites. Participants expected an average pain intensity of 33.6 \pm 4.5 VAS units at the control site compared with $23.2 \pm 4.9$ at the placebo site $(T(8)=4.04, p=0.004)$. Actual pain experienced during conditioning was also significantly lower at the placebo site, with an average intensity rating of $38.6 \pm$ 6.3 for the control site compared with $24.3 \pm 4.2$ for the placebo site $(T(8)=4.6$, $\mathrm{p}=0.002$ ). Additionally, retrospective pain intensity ratings were lower for stimuli administered to the placebo site $(42.0 \pm 6.8$ VAS units for the control site compared with $23.8 \pm 4.7$ VAS units for the placebo site; $T(8)=5.9, p<0.001)$. Similar results were found for the averaged pain unpleasantness ratings (expected control vs. placebo: $27.9 \pm 5.5$ vs. $17.6 \pm 4.7, \mathrm{~T}(8)=3.4, \mathrm{p}=0.009$; concurrent control vs. placebo: $34.4 \pm 6.7$ vs. $19.2 \pm 3.7, \mathrm{~T}(8)=4.1, \mathrm{p}=0.003$; remembered control vs. placebo: $38.7 \pm 7.2$ vs. $14.8 \pm 3.9, T(8)=5.4, p=0.001$ ). These results indicate that the participants initially expected the placebo cream to reduce pain, and that conditioning produced the intended experience of analgesia.

Before the light was turned off in the experimental sessions, participants again received 8 stimuli at one of the two skin sites, depending on the condition. Stimulus intensity was surreptitiously decreased when administered at the placebo site. Average pain intensity was $39.9 \pm 5.5$ VAS units for the control night compared to $16.7 \pm 6.5$ for the placebo night $(T(8)=4.60, p=0.002$, Paired T-test). Similar results were found for pain unpleasantness, with an average of $34.6 \pm 5.6$ and $14.6 \pm 6.1$ for the control and placebo night, respectively $(T(8)=4.66$, $\mathrm{p}=0.002$ ). This additional manipulation was performed immediately before sleep in order to re-evoke the participant's expectation that the placebo cream would provide nocturnal relief. 


\subsection{Nocturnal Placebo Effect: Subjective Ratings}

To assess the presence of a nocturnal placebo effect, subjective ratings were collected before and after sleep in both experimental sessions (Figure 2). On the evening of the control and placebo nights, participants were asked to assess how much pain they expected to feel during the night and the extent to which they expected the pain to disturb their sleep. On the evening of the placebo night, participants expected the nociceptive stimuli to produce lower nocturnal pain intensity $(T(8)=4.85, p=0.001)$ and unpleasantness $(T(8)=3.58, p=0.007)$ and fewer sleep disturbance $(T(8)=3.12, p=0.014)$. Participants also reported less anticipatory anxiety on the placebo compared with the control night $(T(8)=3.66$, $\mathrm{p}=0.006)$.

In the morning, participants were asked to retrospectively rate their nocturnal experience. Significant reductions were observed in nocturnal pain intensity $(\mathrm{T}(8)=3.13, \mathrm{p}=0.014)$, pain unpleasantness $(\mathrm{T}(8)=3.42, \mathrm{p}=0.009)$, anxiety $(T(8)=2.44, p=0.041)$, and associated sleep disturbance $(T(8)=3.21, p=0.012)$. In addition, participants recalled fewer stimulations on the morning of the placebo compared with the control night (placebo night: $3.1 \pm 0.8$; control night: $4.3 \pm 0.7$; $\mathrm{T}(8)=2.48, \mathrm{p}=0.038)$. 

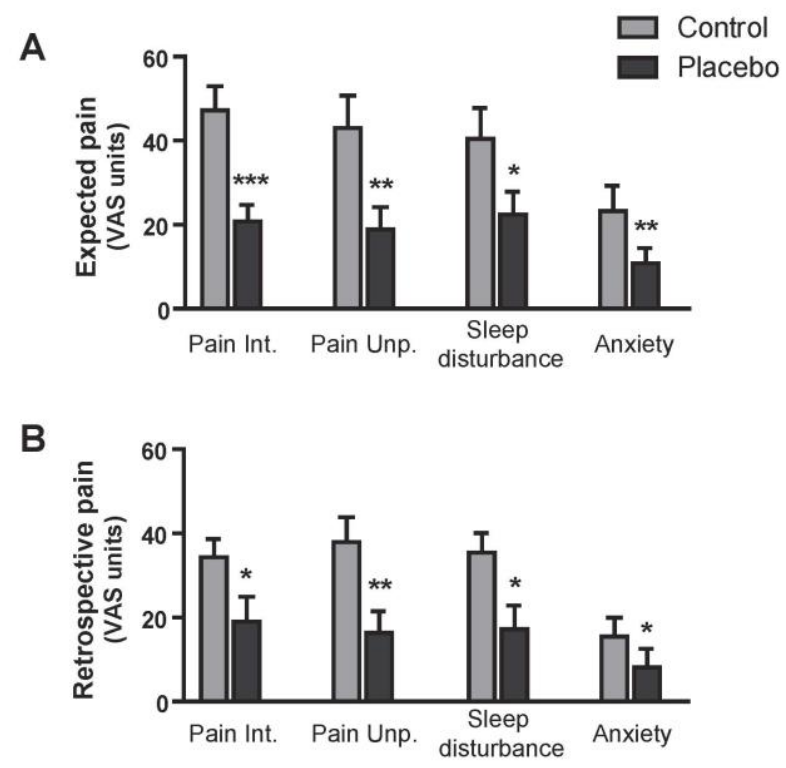

Figure 2. Subjective ratings. Ratings for expected $(\mathbf{A})$ and retrospective (B) pain intensity (Int.) and unpleasantness (Unp.), pain-related sleep disturbance, and anxiety collected in the evening (expected) and morning (retrospective) of the control and placebo nights. Int.: Intensity; Unp.: Unpleasantness. Paired T-test comparing the placebo and control condition: ${ }^{* * *} p<0.001,{ }^{* *} p<0.01,{ }^{*} p<0.05$.

\subsection{Sleep Architecture}

\subsubsection{Polysomnographic Parameters}

Sleep parameters were calculated from the polysomnographic recordings for each overnight session (Table 1). No significant difference in any parameter was observed between the 3 nights (all p's > 0.05), suggesting that sleep architecture was generally stable across sessions. One participant showed longer sleep latency (more than 2 standard deviations above the mean) with correspondingly shorter sleep duration and poorer sleep efficiency (more than 2 standard deviations below the group mean) on the control night, and was therefore removed from the analysis of these three variables. 
Table 1 Sleep parameters recorded with polysomnography during the 3 nights (Mean \pm SEM).

\begin{tabular}{|c|c|c|c|}
\hline & Habituation night & Control night & Placebo night \\
\hline Sleep latency (min) & $12.5 \pm 2.7$ & $10.8 \pm 3.2$ & $9.9 \pm 3.1$ \\
\hline $\begin{array}{l}\text { REM sleep latency } \\
\text { (min) }\end{array}$ & $102.5 \pm 14.8$ & $96.5 \pm 18.2$ & $99.0 \pm 13.4$ \\
\hline Sleep duration (min) & $418.8 \pm 12.9$ & $397.1 \pm 7.3$ & $410.6 \pm 11.7$ \\
\hline Sleep efficiency (\%) & $93.1 \pm 1.6$ & $90.8 \pm 1.2$ & $91.4 \pm 1.6$ \\
\hline Stage $2(\%)$ & $56.8 \pm 2.1$ & $53.4 \pm 2.5$ & $52.8 \pm 1.8$ \\
\hline SWS (\%) & $21.3 \pm 2.5$ & $20.8 \pm 3.0$ & $21.4 \pm 2.4$ \\
\hline REM (\%) & $17.8 \pm 2.0$ & $19.9 \pm 2.3$ & $21.0 \pm 1.5$ \\
\hline
\end{tabular}

\subsubsection{Brain Arousal Responses}

To assess the effect of placebo manipulation on sleep disturbance, nocturnal stimulations were comparably distributed across sleep stages in the control and placebo nights (Table 2; Paired T-tests between the total number of stimulations per night and per sleep stage, all p's $>0.49$ ). Whereas the proportion of arousals produced by the noxious stimuli applied in stage 2 sleep was comparable between the placebo and control nights (Yates corrected $\chi^{2}(1)=0.09, p=0.77$ ), significant differences were found for REM sleep and SWS. During REM sleep, placebo treatment was associated with lower arousal rates (83.2\%) compared with the control night $\left(93.0 \%\right.$; Yates corrected $\left.\chi^{2}(1)=4.49, \mathrm{p}=0.034\right)$. Conversely, during SWS, a significantly higher arousal rate was observed for the placebo (88.8\%) compared with the control night $\left(74.8 \%\right.$; Yates corrected $\chi^{2}(1)=5.67$, $\mathrm{p}=0.017$ ). This suggests that the responsiveness to nociceptive stimuli was modulated differentially by the placebo treatment according to the sleep stage. 
Table 2. Total number of nociceptive stimuli applied and number of brain arousals produced during each sleep stage in the control and placebo nights across all participants.

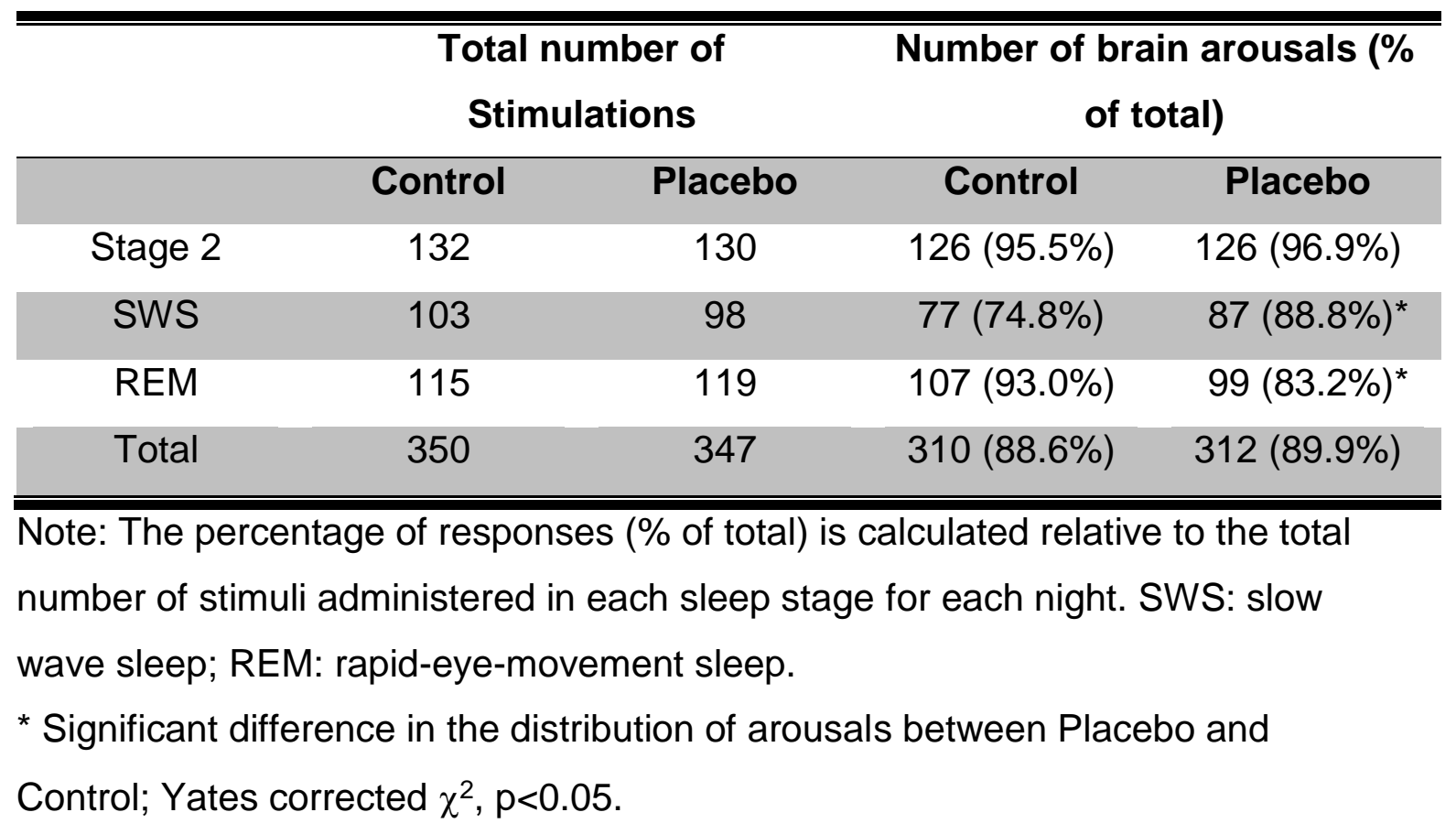

\subsection{Confirmation of a Diurnal Placebo Effect}

For all participants, placebo analgesia was assessed on the last morning after the third polysomnography night (see Figures 1 and 3) as a manipulation check. In this final placebo test, participants still expected to experience less pain following placebo treatment compared with the control condition (expected pain intensity relief: $T(8)=6.99, p<0.001$; expected pain unpleasantness relief: $\mathrm{T}(8)=4.01, \mathrm{p}=0.004$ ). In addition, participants reported statistically significant reductions in pain intensity during concurrent assessments $(T(8)=2.70, p=0.027$; reduced pain unpleasantness: $\mathrm{T}(8)=1.80, \mathrm{p}=0.109$, ns). Retrospective assessments confirmed the presence of a significant analgesic effect of the placebo on both pain intensity $(\mathrm{T}(8)=2.98, \mathrm{p}=0.018)$ and pain unpleasantness $(\mathrm{T}(8)=2.80, \mathrm{p}=0.023)$. 


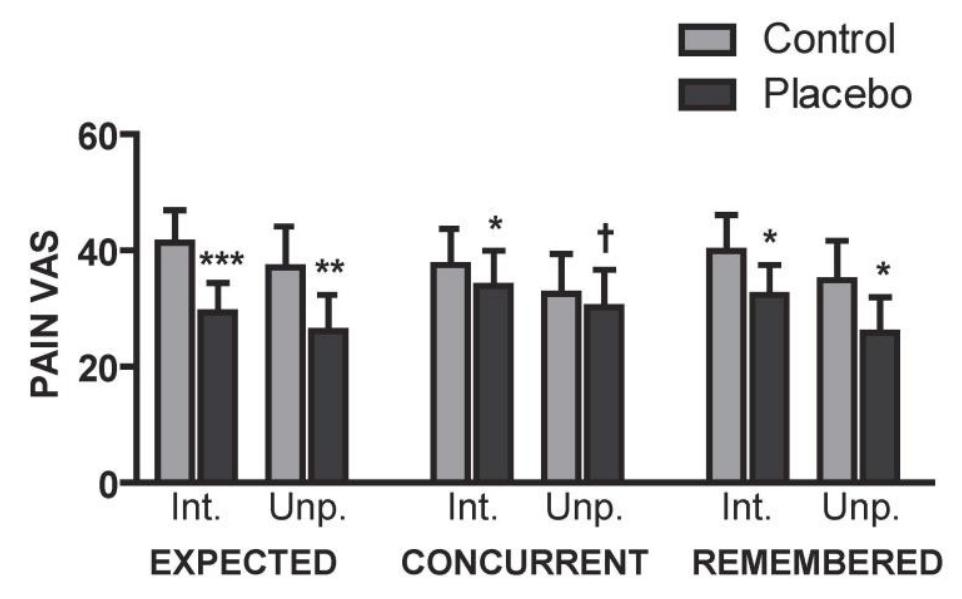

Figure 3. Placebo analgesia observed in the waking state on the last morning (manipulation check). Expected, concurrent, and retrospective pain intensity and unpleasantness measured at the control and placebo sites during the Placebo test block after the third night of testing. Int.: Intensity; Unp.: Unpleasantness. Paired T-test comparing the placebo to the control condition: ${ }^{* \star *} p<0.001 ;{ }^{* *} p<0.01 ;{ }^{*} p<0.05, \dagger p=0.11$.

\section{DISCUSSION}

This is the first experimental study to investigate directly placebo analgesia during sleep. Results suggest that placebo analgesia manipulations performed prior to sleep can modulate the responsiveness to nociceptive stimuli on the following night. In addition to significant nocturnal pain relief reported in the morning following the placebo treatment, participants showed fewer arousals during REM sleep, with an unexpected increase during SWS. This suggests that the lower nocturnal pain and fewer sleep disturbances reported following placebo induction may be due to effects during REM sleep but not SWS.

Several clinical trials have shown improvements in placebo groups relative to pre-treatment baseline in self-reported pain and behavioral measures of sleep 
interference (e.g., [21;54]; [12]; [24]). In addition, meta-analytic reviews have confirmed robust placebo effects in diseases such as insomnia and restless legs syndrome ([40]; [47]; [7]; [23]). A study of fibromyalgia provided further evidence that changes in pain after the administration of a placebo treatment were highly correlated with measures of sleep quality and sleep disturbance ([57]), suggesting that the placebo analgesia effects may generalize to nocturnal pain and/or relate to improved sleep.

Experimental studies using auditory evoked potentials have demonstrated that electrophysiological features associated with the detection of salient or deviant stimuli during waking states are also observed during sleep, but in REM sleep exclusively ([6]; [50];[18]). Pre-sleep instructions to engage participant attention and threats of electric shock to induce motivation can also modulate the amplitude of brain potentials evoked by deviant stimuli as well as the accuracy of behavioral responses during REM sleep ([67]; [60]). Accordingly, the reduction in the responsiveness to noxious heat following placebo administration in the present study was observed exclusively during REM sleep. In line with our previous findings ([33]), this suggests that REM sleep plays a role in processing expectations, which may in turn modulate responses to nocturnal sensory inputs.

During SWS, the placebo treatment was associated with an unexpectedly higher proportion of sleep arousals induced by the nociceptive stimuli. More arousals in SWS on the placebo night may reflect the discrepancy between bottom-up nociceptive signals registered by the brain and the expectations that these noxious stimuli would be less painful (i.e., high prediction error). Reciprocally, noxious inputs congruent with expectations on the control night might involve more efficient gating mechanisms to protect SWS against inopportune sleep disturbances, consistent with basic energy conservation principles central to some functional theories of sleep (e.g., [58]; [55]). 
Some limitations of the present study should be considered in interpreting those findings. The assessment of nocturnal pain, anxiety and sleep disturbances was based on retrospective reports obtained in the morning. This procedure is difficult to circumvent in sleep research and it may introduce confounding effects associated with memory distortions and biases. Furthermore, the within-subject design with three recording nights allowed detecting significant placebo-related effects in brain arousals during sleep but the sample size is admittedly small. Results are nevertheless consistent with our previous findings ([33]) and with the current knowledge on placebo effects and the role of REM sleep in learning and memory ([34]). Future polysomnographic studies are needed to confirm these effects in larger samples and diverse populations, including patients suffering from painful conditions.

In this study, the observation that placebo analgesia resulted in lower nocturnal pain and anxiety and fewer sleep disturbances suggests that conditioning effects and suggestions given before sleep remain active during sleep to some extent. Such effects merit further attention, particularly in clinical practice, where patients may have positive or negative expectations. The association between chronic pain and poor sleep is well-recognized (e.g. [22;30]), and may relate to poor expectations developed through learning processes. The fundamental role of learning in pain chronification is gaining support (e.g., [5];[61;62]). Such learning models integrate the basic theoretical notion of expectation ([26]), which is also a key factor in predicting various clinical outcomes (e.g., [41] [20] [17]). The present findings should motivate a deeper examination of the role of sleep stages in the consolidation of learned expectations and in modulating responses to pain treatments during both sleep and waking state. 


\section{Reference List}

[1] Amanzio M, Benedetti F. Neuropharmacological dissection of placebo analgesia: expectation-activated opioid systems versus conditioningactivated specific subsystems. Journal of Neuroscience 1999;19:484-494.

[2] Amanzio M, Benedetti F, Porro CA, Palermo S, Cauda F. Activation likelihood estimation meta-analysis of brain correlates of placebo analgesia in human experimental pain. Hum Brain Mapp 2013;34:738-752.

[3] American Sleep Disorders Association. EEG arousals: scoring rules and examples: a preliminary report from the Sleep Disorders Atlas Task Force of the American Sleep Disorders Association. Sleep, Vol. 15 1992. pp. 173184.

[4] Anderson KL, Rajagovindan R, Ghacibeh GA, Meador KJ, Ding M. Theta oscillations mediate interaction between prefrontal cortex and medial temporal lobe in human memory. Cereb Cortex 2010;20:1604-1612.

[5] Apkarian AV, Baliki MN, Geha PY. Towards a theory of chronic pain. Prog Neurobiol 2009;87:81-97.

[6] Bastuji H, Garcia-Larrea L, Franc C, Mauguiere F. Brain processing of stimulus deviance during slow-wave and paradoxical sleep: a study of human auditory evoked responses using the oddball paradigm. J Clin Neurophysiol 1995;12:155-167. 
[7] Belanger L, Vallieres A, Ivers H, Moreau V, Lavigne G, Morin CM. Metaanalysis of sleep changes in control groups of insomnia treatment trials. $J$ Sleep Res 2007;16:77-84.

[8] Benedetti F, Arduino C, Amanzio M. Somatotopic activation of opioid systems by target-directed expectations of analgesia. Journal of Neuroscience 1999;19:3639-3648.

[9] Benedetti F, Pollo A, Lopiano L, Lanotte M, Vighetti S, Rainero I. Conscious Expectation and Unconscious Conditioning in Analgesic, Motor, and Hormonal Placebo/Nocebo Responses. J Neurosci 2003;23:4315.

[10] Bingel U, Lorenz J, Schoell E, Weiller C, Buchel C. Mechanisms of placebo analgesia: rACC recruitment of a subcortical antinociceptive network. Pain 2006;120:8-15.

[11] Braun AR, Balkin TJ, Wesenten NJ, Carson RE, Varga M, Baldwin P, Selbie S, Belenky G, Herscovitch P. Regional cerebral blood flow throughout the sleep-wake cycle. An H2(15)O PET study. Brain 1997;120 ( Pt 7):11731197.

[12] Breuer B, Sperber K, Wallenstein S, Kiprovski K, Calapa A, Snow B, Pappagallo M. Clinically significant placebo analgesic response in a pilot trial of botulinum B in patients with hand pain and carpal tunnel syndrome. Pain Med 2006;7:16-24. 
Placebo analgesia during sleep

[13] Buchsbaum MS, Hazlett EA, Wu J, Bunney WE, Jr. Positron emission tomography with deoxyglucose-F18 imaging of sleep.

Neuropsychopharmacology $2001 ; 25:$ S50-S56.

[14] Campbell K, Muller-Gass A. The extent of processing of near-hearing threshold stimuli during natural sleep. Sleep 2011;34:1243-1249.

[15] Colloca L, Lopiano L, Lanotte M, Benedetti F. Overt versus covert treatment for pain, anxiety, and Parkinson's disease. Lancet Neurol 2004;3:679-684.

[16] Colloca L, Sigaudo M, Benedetti F. The role of learning in nocebo and placebo effects. Pain 2008;136:211-218.

[17] Cormier S, Lavigne GL, Choiniere M, Rainville P. Expectations predict chronic pain treatment outcomes. Pain 2016;157:329-338.

[18] Cote KA, Etienne L, Campbell KB. Neurophysiological evidence for the detection of external stimuli during sleep. Sleep 2001;24:791-803.

[19] Diekelmann S, Born J. The memory function of sleep. Nat Rev Neurosci 2010;11:114-126.

[20] Dionne CE, Bourbonnais R, Fremont P, Rossignol M, Stock SR, Larocque I. A clinical return-to-work rule for patients with back pain. CMAJ 2005;172:1559-1567. 
[21] Dogra S, Beydoun S, Mazzola J, Hopwood M, Wan Y. Oxcarbazepine in painful diabetic neuropathy: a randomized, placebo-controlled study. Eur $\mathrm{J}$ Pain 2005;9:543-554.

[22] Fishbain DA, Cole B, Lewis JE, Gao J. What is the evidence for chronic pain being etiologically associated with the DSM-IV category of sleep disorder due to a general medical condition? A structured evidence-based review. Pain Med 2010;11:158-179.

[23] Fulda S, Wetter TC. Where dopamine meets opioids: a meta-analysis of the placebo effect in restless legs syndrome treatment studies. Brain 2008;131:902-917.

[24] Gabis L, Shklar B, Baruch YK, Raz R, Gabis E, Geva D. Pain reduction using transcranial electrostimulation: a double blind "active placebo" controlled trial. J Rehabil Med 2009;41:256-261.

[25] Hobson JA. REM sleep and dreaming: towards a theory of protoconsciousness. Nat Rev Neurosci 2009;10:803-813.

[26] Ingvar M. Learning mechanisms in pain chronification--teachings from placebo research. Pain 2015;156 Suppl 1:S18-S23.

[27] Jasper $\mathrm{HH}$. The ten-twenty electrode system of the International Federation. EEG and Clinical Neurophysiology, Vol. 10 1958. pp. 371-375. 
Placebo analgesia during sleep

[28] Jensen KB, Kaptchuk TJ, Chen X, Kirsch I, Ingvar M, Gollub RL, Kong J. A Neural Mechanism for Nonconscious Activation of Conditioned Placebo and Nocebo Responses. Cereb Cortex 2015;25:3903-3910.

[29] Jones MW, Wilson MA. Theta rhythms coordinate hippocampal-prefrontal interactions in a spatial memory task. PLoS Biol 2005;3:e402.

[30] Kelly GA, Blake C, Power CK, O'Keeffe D, Fullen BM. The association between chronic low back pain and sleep: a systematic review. Clin J Pain $2011 ; 27: 169-181$.

[31] Kirsch I, Lynn SJ, Vigorito M, Miller RR. The role of cognition in classical and operant conditioning. J Clin Psychol 2004;60:369-392.

[32] Klimesch W, Doppelmayr M, Stadler W, Pollhuber D, Sauseng P, Rohm D. Episodic retrieval is reflected by a process specific increase in human electroencephalographic theta activity. Neurosci Lett 2001;302:49-52.

[33] Laverdure-Dupont D, Rainville P, Montplaisir J, Lavigne G. Changes in rapid eye movement sleep associated with placebo-induced expectations and analgesia. J Neurosci 2009;29:11745-11752.

[34] Laverdure-Dupont D, Rainville P, Montplaisir J, Lavigne G. Relief expectation and sleep. Rev Neurosci 2010;21:381-395. 
[35] Lavigne G, Zucconi M, Castronovo C, Manzini C, Marchettini P, Smirne S. Sleep arousal response to experimental thermal stimulation during sleep in human subjects free of pain and sleep problems. Pain 2000;84:283-290.

[36] Maquet P, Laureys S, Peigneux P, Fuchs S, Petiau C, Phillips C, Aerts J, Del Fiore G, Degueldre C, Meulemans T, Luxen A, Franck G, Van Der LM, Smith C, Cleeremans A. Experience-dependent changes in cerebral activation during human REM sleep. Nat Neurosci 2000;3:831-836.

[37] Maquet P, Peters J, Aerts J, Delfiore G, Degueldre C, Luxen A, Franck G. Functional neuroanatomy of human rapid-eye-movement sleep and dreaming. Nature 1996;383:163-166.

[38] Maquet P, Ruby P, Maudoux A, Albouy G, Sterpenich V, Dang-Vu T, Desseilles M, Boly M, Perrin F, Peigneux P, Laureys S. Human cognition during REM sleep and the activity profile within frontal and parietal cortices: a reappraisal of functional neuroimaging data. Prog Brain Res 2005;150:219-227.

[39] Marzano C, Ferrara M, Mauro F, Moroni F, Gorgoni M, Tempesta D, Cipolli C, De GL. Recalling and forgetting dreams: theta and alpha oscillations during sleep predict subsequent dream recall. J Neurosci 2011;31:66746683.

[40] McCall WV, D'Agostino R, Jr., Dunn A. A meta-analysis of sleep changes associated with placebo in hypnotic clinical trials. Sleep Med 2003;4:57-62. 
[41] Mondloch MV, Cole DC, Frank JW. Does how you do depend on how you think you'll do? A systematic review of the evidence for a relation between patients' recovery expectations and health outcomes. CMAJ 2001;165:174179.

[42] Montgomery GH, Kirsch I. Classical conditioning and the placebo effect. Pain 1997;72:107-113.

[43] Morris JS, Ohman A, Dolan RJ. Conscious and unconscious emotional learning in the human amygdala. Nature 1998;393:467-470.

[44] Munday JA. Instrumentation and electrode placement. Respir Care Clin N Am 2005;11:605-15, viii.

[45] Nishida M, Pearsall J, Buckner RL, Walker MP. REM sleep, prefrontal theta, and the consolidation of human emotional memory. Cereb Cortex 2009;19:1158-1166.

[46] Nofzinger EA, Mintun MA, Wiseman M, Kupfer DJ, Moore RY. Forebrain activation in REM sleep: an FDG PET study. Brain Res 1997;770:192-201.

[47] Perlis ML, McCall WV, Jungquist CR, Pigeon WR, Matteson SE. Placebo effects in primary insomnia. Sleep Med Rev 2005;9:381-389.

[48] Petrovic P, Kalso E, Petersson KM, Ingvar M. Placebo and opioid analgesia-- imaging a shared neuronal network. Science 2002;295:17371740. 
Placebo analgesia during sleep

[49] Poe GR, Walsh CM, Bjorness TE. Cognitive neuroscience of sleep. Prog Brain Res 2010;185:1-19.

[50] Pratt H, Berlad I, Lavie P. 'Oddball' event-related potentials and information processing during REM and non-REM sleep. Clin Neurophysiol 1999;110:53-61.

[51] Price DD, McGrath PA, Rafii A, Buckingham B. The validation of visual analog scales as ratio scale measures for chronic and experimental pain. Pain 1983;17:45-56.

[52] Price DD, Milling LS, Kirsch I, Duff A, Montgomery GH, Nicholls SS. An analysis of factors that contribute to the magnitude of placebo analgesia in an experimental paradigm. Pain 1999;83:147-156.

[53] Rechtschaffen A, Kales A. A manual of standardized terminology, techniques and scoring system for sleep stages of human subjects. Bethesda, Md, USA: National Institute of Neurological Diseases and Blindness, Neurological Information Network, 1968.

[54] Richter RW, Portenoy R, Sharma U, Lamoreaux L, Bockbrader H, Knapp LE. Relief of painful diabetic peripheral neuropathy with pregabalin: a randomized, placebo-controlled trial. J Pain 2005;6:253-260.

[55] Roth TC, Rattenborg NC, Pravosudov VV. The ecological relevance of sleep: the trade-off between sleep, memory and energy conservation. Philos Trans R Soc Lond B Biol Sci 2010;365:945-959. 
[56] Ruby P, Caclin A, Boulet S, Delpuech C, Morlet D. Odd sound processing in the sleeping brain. J Cogn Neurosci 2008;20:296-311.

[57] Russell IJ, Crofford LJ, Leon T, Cappelleri JC, Bushmakin AG, Whalen E, Barrett JA, Sadosky A. The effects of pregabalin on sleep disturbance symptoms among individuals with fibromyalgia syndrome. Sleep Med 2009;10:604-610.

[58] Siegel JM. Clues to the functions of mammalian sleep. Nature 2005;437:1264-1271.

[59] Sterpenich V, Schmidt C, Albouy G, Matarazzo L, Vanhaudenhuyse A, Boveroux P, Degueldre C, Leclercq Y, Balteau E, Collette F, Luxen A, Phillips $C$, Maquet $P$. Memory reactivation during rapid eye movement sleep promotes its generalization and integration in cortical stores. Sleep 2014;37:1061-1075B.

[60] Takahara M, Nittono H, Hori T. Effect of voluntary attention on auditory processing during REM sleep. Sleep 2006;29:975-982.

[61] Vachon-Presseau E, Centeno MV, Ren W, Berger SE, Tetreault P, Ghantous M, Baria A, Farmer M, Baliki MN, Schnitzer TJ, Apkarian AV. The Emotional Brain as a Predictor and Amplifier of Chronic Pain. J Dent Res 2016;95:605-612.

[62] Vachon-Presseau E, Tetreault P, Petre B, Huang L, Berger SE, Torbey S, Baria AT, Mansour AR, Hashmi JA, Griffith JW, Comasco E, Schnitzer TJ, 
Baliki MN, Apkarian AV. Corticolimbic anatomical characteristics predetermine risk for chronic pain. Brain 2016;139:1958-1970.

[63] Velluti RA. Interactions between sleep and sensory physiology. J Sleep Res 1997;6:61-77.

[64] Voudouris NJ, Peck CL, Coleman G. The role of conditioning and verbal expectancy in the placebo response. Pain 1990;43:121-128.

[65] Wager TD, Rilling JK, Smith EE, Sokolik A, Casey KL, Davidson RJ, Kosslyn SM, Rose RM, Cohen JD. Placebo-induced changes in FMRI in the anticipation and experience of pain. Science 2004;303:1162-1167.

[66] Wager TD, Scott DJ, Zubieta JK. Placebo effects on human \{micro\}-opioid activity during pain. Proc Natl Acad Sci U S A 2007;104:11056-11061.

[67] Williams HL. The problem of defining depth of sleep. Res Publ Assoc Res Nerv Ment Dis 1967;45:277-287.

[68] Zubieta JK, Stohler CS. Neurobiological mechanisms of placebo responses. Ann N Y Acad Sci 2009;1156:198-210. 